\title{
A EDUCAÇÃO DOS CORPOS INFANTIS NO PROJETO MATO-GROSSENSE DE FORMAÇÃO DO CIDADÃO REPUBLICANO (1910-1930)
}

\author{
Elizabeth Figueiredo de Sál
}

RESUMO: O artigo teve o objetivo de analisar as finalidades para a educaçáo do corpo infantil que permearam a implantaçáo da disciplina Gymnastica no ensino público primário matogrossense na Primeira República. Inicialmente, o estudo analisou a influência higienista na organizaçáo do espaço e do tempo dos grupos escolares para a formação da criança saudável. Em seguida, procurou compreender como a disciplina Gymnastica foi idealizada e colocada em prática no cotidiano escolar. Para a realização da pesquisa, foram utilizadas fontes documentais localizadas no Arquivo Público do Estado de Mato Grosso.

Palavras-chave: Educação física. Ginástica. História da infância. Grupos escolares. História da educação.

\section{The education of children's bodies in the Mato Grosso project for the formation of the republican citizen (1910-1930)}

ABSTRACT: The article aimed to analyze the purposes for the education of the infantile body that permeated the implantation of the discipline Gymnastics in the primary public education of Mato Grosso in the First Republic. Initially, it analyzed the

\footnotetext{
${ }^{1}$ Universidade Federal de Mato Grosso, Instituto de Educação - Cuiabá (MT), Brasil. E-mail: elizabethfsa1@gmail.com
}

DOI: $10.1590 / C C 0101-32622018178353$ 
hygienist influence in the organization of the space and the time of the school groups for the formation of healthy children. Next, it tried to understand how the discipline Gymnastics was idealized and implemented in the school routine. To accomplish the research, documentary sources located in the Public Archive of the state of Mato Grosso were used.

Keywords: Physical education. Gymnastics. History of childhood. School groups. History of education.

\section{INTRODUÇÃO}

Ninguém desconhece hoje a importância da ginástica, como parte da educação, pela influência imediata que ela exerce na saúde e no desenvolvimento físico dos indivíduos.

O homem não é só um ser intelectual e moral, é também um ente físico; logo, a escola, que o tem de educar, deve curar não só da sua inteligência e do seu coração, mas também do seu corpo; não deve educar meio homem, porém o homem todo.

Pe. Ernesto Camilo Barreto (1874)

om essas palavras, o Inspetor Geral dos Estudos da Província de Mato Grosso, Padre Ernesto Camilo Barreto (MATO GROSSO, 1874), ao tratar sobre a educação pública primária, defende a importância da formação completa da criança, alegando "a necessidade da aplicação da ginástica às escolas primárias; porque só pela tríplice educação poderá ela desempenhar sua missão civilizadora”. Tal orientação tem como referência as discussóes que vinham sendo travadas no cenário nacional, nas quais a escola, bem como a disciplina de ginástica, era compreendida como um instrumento para a reforma social e a propulsora do progresso e da civilização dentro de um amplo projeto 
político-social, sendo uma bandeira de luta para monarquistas, conservadores e, especialmente, liberais e republicanos (SOUZA, 2000).

A proposta de educação do corpo apregoada por Camilo Barreto não foi concretizada no Estado de Mato Grosso até o regime político republicano, com a implantação, em 1910, dos grupos escolares pelos normalistas paulistas Leowigildo Martins de Mello e Gustavo Kuhlmann. Mello, com argumento similar ao de Camilo Barreto, defendeu o uso da ginástica para a formação integral da criança, afirmando que "não seria, portanto, natural que a escola cuidasse dos educandos moral e intelectualmente, desprezando a educação física" (MATO GROSSO, 1911, p. 10-11).

A implantação da Educação Física nesse modelo escolar fazia parte de um projeto nacional de formaçáo do novo cidadão para atuar na sociedade brasileira. Um cidadão com formação integral em seus aspectos físico, intelectual e psicológico.

Nesse sentido, o presente artigo teve o objetivo de analisar as finalidades para a educação do corpo infantil que permearam a implantação da disciplina Gymnastica no ensino público primário matogrossense, pois, conforme Forquin (1993, p. 90), "o modo pelo qual se acham organizados, delimitados, classificados, separados, os saberes veiculados na escola influencia, com efeito, a construção da identidade entre os alunos". Inicialmente, abordam-se a implantação dos grupos escolares e a influência higienista na sua organização para, em seguida, perceber como a disciplina Gymnastica foi pensada e posta em prática nesse modelo escolar. A análise fundamenta-se nas obras de Goodson (1995), ao se referir à história do Currículo; em Chervel (1990), no que concerne à história das disciplinas escolares; e em Chartier (1990) e seu conceito de representaçôes sociais (1990).

\section{GRUPOS ESCOLARES E A RACIONALIZAÇÃO DA ORGANIZAÇÃO DO PROCESSO FORMATIVO DA INFÂNCIA}

A preocupação com o desenvolvimento saudável da criança esteve presente desde a formação dos grupos escolares em Mato Grosso, criados por meio da Resolução no 508, de 16 de outubro de 1908, e instalados, em 1910, por Leowigildo Martins de Mello e Gustavo Fernando 
Kuhlmann, ambos formados pela Escola Normal Caetano de Campos e convidados em missão de trabalho para reorganizar a Instrução Pública do Estado de Mato Grosso.

Voltado para formar quem seriam os futuros cidadãos republicanos, esse modelo de escolarização foi organizado dentro de uma nova cultura escolar, no sentido de dar maior racionalização à organização e ao processo formativo da infância, centrando-se na formação do indivíduo enquanto participante do processo produtivo e da vida política do país, procurando "cultivar um corpo belo, forte, saudável, higiênico, ativo, ordeiro, racional, em contraposição àquele considerado feio, fraco, doente, sujo e preguiçoso" (VAGO, 1999).

A preocupação com a higiene do espaço escolar, principalmente com as salas de aula, estava presente no Regulamento Interno dos Grupos Escolares:

1 - a disposição da mobília nas salas de aulas terá por base a projeção da luz, de modo que os alunos a recebam, principalmente do alto e pelo lado esquerdo; [...]

4 - durante o recreio e após a retirada dos alunos deverão ser abertas todas as janelas a fim de serem arejadas as salas;

5 - o pavimento deverá ser lavado semanalmente com líquido anti-séptico apropriado e as paredes ao menos, caiadas duas vezes por ano;

6 - a limpeza do assoalho será feita diariamente, sendo preferível aplicar um pano úmido, a varrer seco (MATO GROSSO, 1916).

Cada sala deverá conter vinte carteiras completas e mais três bancos isolados traseiros. As carteiras, de acordo com as dimensóes da sala, serão em três ou quatro filas, devendo haver entre esses espaços $0,75 \mathrm{~ms}$ e entre a parede e as carteiras, espaço de $0,80 \mathrm{~ms}$., exceto a parte anterior, que terá espaço suficiente para a colocação da mesa do profes- 
sor. As carteiras escolares serão colocadas de maneira que os alunos recebam a maior intensidade de luz do alto e pelo lado esquerdo (MATO GROSSO, 1916).

Não somente a construção arquitetônica e o ambiente deveriam se apresentar adequados ao ensino. Os materiais também obedeciam ao preceito médico-higienista, como é possível observar no Regulamento Interno (MATO GROSSO, 1916):

Art. $6^{\circ}-$ A mobília escolar constará da que for determinada pelo Diretor Geral da Instrução Pública, devendo sua construção ter por base os modelos que mais facilitem a inspeção, a responsabilidade individual dos alunos e a satisfação dos preceitos higiênicos.

Art. $9^{\circ}$ - Haverá nas classes e na sala da Diretoria os objetos necessários ao ensino e os exigidos pelo preceito da higiene conforme o modelo, a qualidade e a quantidade determinada pela Diretoria Geral da Instrução Pública.

Os higienistas acentuavam sobremaneira o mal causado às crianças pelas péssimas instalaçóes escolares, ressaltando que a falta de espaços e materiais higienicamente concebidos era prejudicial à saúde e à aprendizagem do aluno (FARIA FILHO; VIDAL, 2000).

Intimamente relacionados à construção da identidade da criança, os lugares construídos alicerçaram os tempos educativos, isto é, os ritmos que regularam a dinâmica da escola e os comportamentos das pessoas que protagonizaram as experiências de escolarização. Assim, "os relógios escolares, ao regular a conduta diária, possibilitavam a aprendizagem da temporalidade e garantiam a internalização dos valores da exatidão, da aplicação e de regularidade" (ESCOLANO, 2001, p. 44). Sobre o assunto, Elias (1998, p. 14) afirma que

ao crescer, com efeito, toda criança vai-se familiarizando com o "tempo" como símbolo de uma instituição social cujo caráter coercitivo ela experimenta desde cedo. 
Se, no decorrer de seus primeiros dez anos de vida, ela não aprender a desenvolver o sistema de autodisciplina conforme a essa instituição, se não aprender a se portar e a modelar sua sensibilidade em função do tempo, serlhe-á muito difícil, se não impossível, desempenhar o papel de um adulto no seio dessa sociedade.

Desse modo, à escola caberia a tarefa de conformar a criança com os hábitos e valores no contexto social em que estava inserida para a sua atuação na própria sociedade e, mais especificamente, no mundo do trabalho.

A preocupação com o tempo escolar e a influência da sua organização na formação da infância fundamentou as reformas da Instrução Pública de Mato Grosso de 1910 e 1927, pois a escola, transformada em espaço responsável pela formação do futuro cidadão (produtivo, disciplinado, ordeiro e, consequentemente, cumpridor de seus deveres) não poderia ter o seu tempo desperdiçado, mas, contrariamente, deveria utilizá-lo de forma racional (SÁ, 2006).

O Regulamento da Instrução Pública (MATO GROSSO, 1910) instituiu como primeiro dia letivo o $1^{\circ}$ dia útil após 31 de janeiro, porém não determinou o término do ano escolar, não deixando claro o número de dias letivos nem tampouco a carga horária anual obrigatória. O calendário escolar ganhou mais clareza e determinação por meio do Regimento Interno dos Grupos Escolares (MATO GROSSO, 1916), que estabeleceu a duração do curso em 4 anos, determinando: o início e o término do ano letivo (de $1^{\circ}$ de fevereiro a 30 de novembro); a carga horária diária de aulas (das $12 \mathrm{~h} 00$ às 17h00); a suspensão das aulas por ocasião de domingos, feriados nacionais e estaduais, em dias determinados pelo governo, e no período de $1^{\circ}$ de dezembro a 30 de janeiro; e a oficialização do intervalo das aulas (o recreio), tendo uma duração de 30 a 40 minutos.

Como a definição do calendário escolar é resultante também de uma organização sociocultural, a sociedade interferiu diretamente na organização temporal dos grupos escolares, provocando o recesso no meio do ano letivo. Esse recesso deveu-se às festas de Sáo João, comemoradas por diversas famílias, o que ocasionava uma grande variedade de eventos espalhados pelos distritos, envolvendo um grande número de pessoas por vários dias, e diminuindo, com isso, a frequência dos alunos nesse período. 
Além do calendário, foram estipulados também os horários das aulas durante a semana, obedecendo à distribuição do tempo de acordo com a disciplina. Para Mello, "uma escola dotada de bom horário torna seu serviço mais fácil para mestres e alunos e oferece resultados mais fecundos", além de preparar "os alunos para terem, mais tarde, ordem na vida, que é, sua dignidade, e pontualidade, que é força” (MATO GROSSO, 1911, p. 5).

Mello explicita as inúmeras vantagens de se organizar o tempo escolar, mostrando a importância dessa organização nas formaçóes física, moral e intelectual da criança:

A sucessão regular dos exercícios dá ao estudo variedade, movimento e animação, ao mesmo tempo que estimula a aplicação e evita o cansaço; excita a atenção dos indolentes, atraindo-a para assuntos variados; dá coragem aos que, não tendo aptidão para todas as disciplinas, esperam com impaciência o momento do exercício em que se podem salientar; evita a irreflexão de alunos que a custa de uns se poderia dedicar mais ao conhecimento de outros estados; evita a falta de tempo, facilita o serviço da classe. [...] São estas, dentre outras, as razóes que pugnam em prol dos bons meios de empregar o tempo escolar (MATO GROSSO, 1911, p. 6).

Nesse sentido, o horário semanal dos grupos escolares foi organizado segundo os preceitos pedagógicos que dizem respeito à ordem, à extensão e ao desenvolvimento das liçôes. São eles: a necessidade de reservar o primeiro período das aulas para as disciplinas que requisitam maior esforço de atenção do aluno; "intercalar, quando possível, exercícios de fácil execução entre as outras disciplinas para descanso do aluno”; por isso, as aulas intercalavam as disciplinas que exigiam mais "esforço" do aluno com uma mais "leve"; por fim, "atender a que, no primeiro ano, quando uma das seçóes estiver em leitura, as outras se ocupem em trabalhos auxiliares da disciplina" (MATO GROSSO, 1910, s/p).

Com essa organização do tempo escolar implementada nos grupos escolares, surgiu o recreio, com a finalidade de que as crianças pudessem descansar o físico e a mente para retornarem às aulas, adequando-se aos preceitos higiênicos da época. De acordo com os artigos 43, 44 e 45 do regulamento que instituiu oficialmente os recreios, os alunos, du- 
rante esse intervalo, teriam uma "liberdade vigiada", ficando sob a guarda de um professor do mesmo sexo, não podendo este se afastar um só momento da companhia dos alunos, sendo o responsável pelas ocorrências. Os pátios do recreio deveriam ser vastos, planos, perfeitamente limpos e arborizados, e com uma cobertura, para os dias de chuva.

A organização do tempo nos grupos escolares implicou em uma mudança drástica em alguns dos aspectos da vida escolar e familiar. Tanto as crianças quanto os pais e educadores tiveram de se adaptar a cumprir um calendário determinado, com horários rígidos, imposto de modo coercitivo, pois até então estavam habituados com a informalidade do funcionamento das escolas isoladas. A organização do tempo e do espaço escolar demonstrou ser de extrema importância para a racionalização das atividades escolares, bem como para a formação do cidadáo, educando-o à obediência e aos hábitos de ordem e de trabalho.

\section{A IMPLANTAÇÃO DA GYMNASTICA NAS ESCOLAS PÚBLICAS PRIMÁRIAS MATO-GROSSENSES}

Ao organizar o currículo dos Grupos Escolares e da Escola Modelo, Mello defendeu a introdução da Gymnastica no ensino primário mato-grossense, pois, em sua formação na Escola Normal "Caetano de Campos", teve acesso tanto à disciplina quanto a "exercicios militares" e ao estágio na Escola Modelo (anexa à sua instituição), na qual a prática já estava presente do $1^{\circ}$ ao $5^{\circ}$ ano curricular.

Tendo como referência sua experiência nessas escolas, ele organizou o currículo das escolas graduadas em Mato Grosso introduzindo no programa da Escola Modelo a Gymnastica todos os dias, nas quatro séries primárias, em diferentes momentos do horário escolar. No primeiro ano, a Gymnastica acontecia todos os dias em três ocasióes distintas: os exercícios calistênicos (13h25 às 13h35); a marcha e o canto (16h30 às 16h35); e os jogos ginásticos e o trabalho manual (16h35 às 17h00). No segundo ano, três vezes na semana, em dois momentos: das $14 \mathrm{~h} 00$ às $14 \mathrm{~h} 20$ e das $16 \mathrm{~h} 35$ às $17 \mathrm{~h} 00$. No terceiro e no quarto ano, os jogos e exercícios militares eram trabalhados das $16 \mathrm{~h} 15$ às $16 \mathrm{~h} 40$ e a Gymnastica era praticada das $16 \mathrm{~h} 40$ às $17 \mathrm{~h} 00$, três vezes por semana. No entanto, 
expóe em seu relatório que não pôde cumprir o programa e que, por isso, limitou as atividades físicas a passeios campestres que, "além de oferecer aos alunos um campo mais hygienico para a bôa respiração e mais próprio para os jogos infantis, tornava mais proveitosas, por serem praticas, as lições de coisas" (MATO GROSSO, 1911, p. 11).

Todo o esforço inicial de Mello em estruturar a Educação Física da criança parece, segundo seu relatório, não ter acontecido na prática escolar conforme o planejado. A falta de estrutura física e de material para as aulas ocasionou um método diferenciado, o qual Mello denominou de "educação física indireta".

Os alunos recebem, diariamente, conselhos de hygiene e de prophylaxia e, sempre que o tempo permitte, são feitos passeios às praças ajardinadas e aos bairros urbanos.

Esses passeios tem dupla vantagem: a) physicologica, o exercício corporal e a respiraçáo ao ar livre e puro;

b) educativa, - attrair a curiosidade infantil para todos os phenomenos naturaes observados durante os passeios. (MATO GROSSO, 1912, p. 20).

É interessante observar que esse mesmo professor conduziu, com mais dois colegas, a organizaçáo do Programa de Ensino para as Escolas Isoladas do Estado (1913); no documento, a disciplina de Gymnastica não foi inserida, pois o currículo dessa modalidade de escola primária só contemplava o ensino de leitura, escrita, cálculo aritmético, língua materna, geografia do Brasil, deveres cívicos e morais e trabalhos manuais.

Com a organização do Regimento Interno dos Grupos Escolares (MATO GROSSO, 1916), a disciplina ganhou novos direcionamentos quanto aos exercícios militares e à ginástica. Em relação aos exercícios militares, os artigos 46 e 47 estabelecem a criação de batalhóes escolares:

Art. 46: Como meio de estímulo poderão ser criados batalhôes escolares sob a condição de que os postos sejam distribuídos pelos alunos que mais se distinguirem por seu comportamento, aplicação e garbo militar. 
Art. 47: Nesses batalhóes será estabelecido o regime mais profícuo à disciplina (MATO GROSSO, 1916).

Souza (2000) ressalta que, à semelhança das organizaçóes militares, os batalhóes escolares reuniam pequenos soldados, representando um corpo unido e harmônico, como deveria ser a pátria. No entanto, não foram encontrados indícios da formação desses batalhóes em Mato Grosso.

Os demais artigos do Capítulo IV do Regulamento (1916) tratam dos exercícios de ginástica, estabelecendo:

Art. 48: Os exercícios de ginástica serão feitos diariamente nas classes ou pelo menos três vezes por semana nos pátios de recreio.

Parágrafo único: quando os exercícios e o local o permitirem, poderão ser reunidas duas ou mais classes.

Art. 49: Os exercícios calisthenicos serão feitos, de preferência na seção feminina (MATO GROSSO, 1916).

Daolio (1995, p. 25) afirma que o corpo é uma síntese da cultura e que, por meio do seu corpo, homens e mulheres vão "assimilando e se apropriando dos valores, normas e costumes sociais, num processo de inCORPOração [...] adquirindo um conteúdo cultural, que se instala no seu corpo, no conjunto de suas expressōes". Nesse sentido, tendo em vista os diferentes papéis sociais a serem incorporados por homens e mulheres na sociedade republicana, a Educação Física tinha um papel preponderante, pois "mulheres fortes e sadias teriam condiçóes de gerarem filhos saudáveis, os quais, estariam mais aptos a defenderem e construírem a Pátria, no caso dos homens, e de se tornarem mães robustas, no caso das mulheres" (CASTELLANI FILHO, 1991, p. 35).

Posteriormente, em 1924, o programa dos grupos escolares foi reestruturado e os conteúdos de Gymnastica foram discriminados para 
todos os anos, não havendo nenhuma observação quanto ao gênero. No entanto, sua carga horária foi reduzida a duas vezes por semana, nos 30 minutos antes do fim da aula.

Mesmo presente no currículo do ensino primário dos grupos escolares desde 1910, a documentação indica que a Educação Física, enquanto disciplina, não conseguiu ser implantada na cultura escolar primária mato-grossense. $\mathrm{O}$ diretor da Escola Modelo, que funcionava anexa à Escola Normal, afirmou em seu relatório:

\section{GYMNASTICA}

A inclusão de alguns minutos de gymnastica no horario semanal das classes provocou alguma reacçáo. A gymnastica é pouco estimada no estabelecimento, não obstante a profunda necessidade de sua pratica methodizada, que deve ter inicio na escola, para invadir, depois, o lar, em bem do vigor e da saude collectivos (MATO GROSSO, 1924).

Maria de Arruda Muller, professora formada na primeira turma da Escola Normal, afirmou em seu depoimento que a Educação Física causou alguns transtornos dentro dos lares:

[...] os professores de ginástica exigiam uma roupa de ginástica, calção para ginástica, roupa apropriada para ginástica. Mas os pais náo concordaram, porque nesse tempo havia muito preconceito. Os pais náo concordavam com certas maneiras de ser da modernidade [...] Houve até pais que tiraram os filhos do colégio por causa de ginástica, mas foi uma coisa passageira. Depois eles viram que era justificável (MULLER apud POUBEL E SILVA, 2000, p. 68).

A documentação aponta que, até os anos finais da Primeira República, a dificuldade de se implantar a disciplina de Gymnastica nas escolas graduadas perdurou por vários motivos (preconceito, dificuldades financeiras de aquisição de materiais, entre outros), desvendando as diferentes representaçóes (CHARTIER, 1990) de educação do corpo da criança mato-grossense naquele período. 


\section{CONSIDERAÇÕES FINAIS}

A educação do corpo da criança, presente nos discursos dos governantes e intelectuais mato-grossenses desde fins do século XIX, foi instituída no currículo da escola pública primária no início do século XX. Entende-se que a constituição dos saberes escolares selecionados para compor o programa curricular das escolas graduadas é a materialização da representação de educação da infância dos governantes e dos intelectuais mato-grossenses, que visava à formação do novo cidadão para atuar na sociedade brasileira. A respeito, Chervel (1990, p. 188) argumenta que "a educação dada e recebida nos estabelecimentos escolares é, à imagem das finalidades correspondentes, um conjunto complexo que não se reduz aos ensinamentos explícitos e programados". Goodson (2001) complementa ao afirmar que a produção e a seleção do conhecimento nunca são inocentes e estão sempre, de algum modo, ligadas às necessidades políticas.

Nesse sentido, percebe-se que os programas da disciplina de Gymnastica tinham como finalidade exercer uma influência moralizadora e higiênica voltada para o desenvolvimento do corpo, da coragem e do patriotismo do futuro cidadáo republicano; também eram voltados para a formação da mulher e para o fortalecimento do seu corpo para o exercício da maternidade.

No entanto, a documentação sugere que a finalidade da Gymnastica, idealizada e inserida nos regulamentos e programas escolares, não se constituiu enquanto prática pedagógica devido, entre vários motivos, à luta de representaçóes existentes na sociedade mato-grossense referentes à educação do corpo infantil.

\section{REFERÊNCIAS}

CASTELLANI FILHO, L. Educaçâo física no Brasil: a história que não se conta. 3. ed. Campinas: Papirus, 1991.

CHARTIER, R. A história cultural: entre práticas e representaçôes. Rio de Janeiro: Bertrand Brasil, 1990.

CHERVEL, A. História das Disciplinas Escolares: reflexôes sobre um campo de pesquisa. Teoria \& Educação, Porto Alegre, n. 2, p. 177-229, 1990. 
DAOLIO, J. Os significados do corpo na cultura e as implicaçóes para a Educação Física. Movimento, n. 2, p. 24-27, jun. 1995.

ELIAS, N. Sobre o Tempo. Rio de Janeiro: Jorge Zahar, 1998.

ESCOLANO, A.B. Arquitetura como Programa. Espaço-Escola e Currículo. In: FRAGO, A.; ESCOLANO, A. Currículo, espaço e subjetividade. Rio de Janeiro: DP\&A, 2001. p. 19-57.

FARIA FILHO, L.M.; VIDAL, D.G. Os tempos e os espaços no processo de institucionalização da escola primária no Brasil. Revista Brasileira de Educação, n. 14, p. 19-34, maio/ago. 2000.

FORQUIN, J.-C. Escola e Cultura: as bases sociais e epistemológicas do conhecimento escolar. Porto Alegre: Artes Médicas, 1993.

GOIS JÚNIOR, E.; BATISTA, J.C.F. A introdução da gymnastica na Escola Normal de Sáo Paulo (1890-1908). Movimento, Porto Alegre, v. 16, n. 3, p. 71 87, jul./set. 2010.

GOODSON, I. Currículo: Teoria e História. Petrópolis: Vozes, 1995.

GOODSON, I. O currículo em mudança: estudos da construçáo social do currículo. Porto: Porto Editora, 2001.

MATO GROSSO. Relatório do Diretor da Instrução Pública, Padre Ernesto Camilo Barreto, 1874. Arquivo Público do Estado de Mato Grosso. Mato Grosso, 1874.

. Governo do Estado de Mato Grosso. Oficio. Lata 1910 B do Arquivo Público de Mato Grosso. Mato Grosso, 1910.

- Relatório do movimento anual da Escola Normal e Modelo anexa apresentado à Secretaria de Estados dos Negócios do Interior, da Justiça e da Fazenda, 1911. Arquivo Público de Mato Grosso. Mato Grosso, 1911.

- Relatório do movimento anual da Escola Normal e Modelo anexa apresentado à Secretaria de Estados dos Negócios do Interior, da Justiça e da Fazenda, 1912. Arquivo Público de Mato Grosso. Mato Grosso, 1912.

- Regulamento Interno dos Grupos Escolares do Estado de Mato Grosso, 1916. Livro 213.Acervo do Grupo de Pesquisa História da Educação e MemóriaUFMT. Mato Grosso, 1916.

POUBEL E SILVA, E.F. de. Escola Normal de Cuiabá (1910-1916): contribuição para a história da formação de professores em Mato Grosso. Dissertação (Mestrado em Educação) - Instituto de Educação, Universidade Federal do Mato Grosso, Cuiabá, 2000. 
SÁ, E.F. De criança a aluno: as representaçôes da escolarização da infância em Mato Grosso (1910-1927). Cuiabá: EdUFMT, 2006.

SOUZA, R.F. de. A militarizaçâo da infância: expressôes do nacionalismo na cultura brasileira. Caderno CEDES, v. 20, n. 52, p. 104-121, 2000. Disponível em: $\leq$ http:// dx.doi.org/10.1590/S0101-32622000000300008>. Acesso em: 25 mar. 2017.

VAGO, T.M. Início e fim do século XX: maneiras de fazer educação física na escola. Caderno CEDES, v. 19, n. 48, p. 30-51, 1999. Disponível em: $\leq$ http:// dx.doi.org/10.1590/S0101-32621999000100003>. Acesso em: 25 mar. 2017.

Recebido em 24 de abril de 2017.

Aprovado em 12 de setembro de 2017. 